\title{
JOHANN BAPTIST METZ Y LA TEOLOGÍA CRISTIANA "DESPUÉS DE AUSCHWITZ" "
}

\author{
Johann Baptist Metz and \\ "Christian Theology after Auschwitz"
}

Johann Baptist Metz e a "teologia cristá
depois de Auschwitz"

Juan Pablo Espinosa Arce ${ }^{2}$

\section{Resumen}

El artículo pretende dar cuenta de algunos elementos centrales de la "teología cristiana después de Auschwitz” del teólogo alemán Johann Baptist Metz. Por medio de la consideración del impacto que la Shoá provocó en el autor, de su

1 El presente artículo se enmarca dentro de una investigación titulada "Aporte de la teología politica de Johann Baptist Metz a la comprensión de la eclesialidad de la fe", correspondiente al trabajo de Tesis para optar al Grado Académico de Licenciado en Teología Fundamental por la Pontificia Universidad Católica de Chile.

2 Chileno. Licenciado en Educación y Profesor de Religión y Filosofía por la Universidad Católica del Maule. Candidato a Magíster en Teología Fundamental por la Pontificia Universidad Católica de Chile. Docente del Centro de Formación Técnica - Instituto Profesional Santo Tomás de la Sede Rancagua, Chile. Correo: jpespinosa@uc.cl

Artículo recibido el 18 enero de 2016 y aprobado para su publicación el 1 marzo de 2016. 
propuesta cristológica realizada a la luz del acontecimiento del holocausto y de la reflexión sobre la necesidad de una mística social y política, Metz pretende rescatar la memoria de la historia del sufrimiento de la cual Auschwitz es el paradigma. La recuperación del recuerdo de los vencidos permitirá que la teología cristiana se sensibilice frente a la realidad dramática de la historia y pueda responder de mejor manera a los nuevos desafíos que se le imponen.

\title{
Palabras clave
}

Johann Baptist Metz, Teología después de Auschwitz, Memoria, Cristología, Mística.

\begin{abstract}
The purpose of the article is to account for some key notions and elements of Johann Baptist Metz's "Christian Theology after Auschwitz". The Christological proposal of the German Theologian is based on the impact of the Shoah (the Holocaust) upon himself and has as purpose a reflection on the necessity for a social and political mysticism. Thus, Metz aims for recovering the memory of the history of suffering, of which Auschwitz is paradigmatic. Recovering the memory of the defeated might make Christian Theology aware of the dramatic reality of History and might help to prepare it to face better the new challenges.
\end{abstract}

\section{Keywords}

Johann Baptist Metz, Theology after Auschwitz, Memory, Christology, Mysticism.

\section{Resumo}

$\mathrm{O}$ artigo pretende apresentar alguns elementos centrais da "teologia cristã depois de Auschwitz", do teólogo alemão Johann Baptist Metz. Por meio da consideração do impacto que a Shoá provocou no autor, de sua proposta cristológica realizada à luz do acontecimento do holocausto e da reflexão sobre a necessidade de uma mística social e política, Metz pretende resgatar a memória da história do sofrimento, da qual Auschwitz é o paradigma. A recuperação das 
recordaçóes dos vencidos permitirá que a teologia cristã se sensibilize frente à realidade dramática da história e possa responder, de melhor maneira, aos novos desafios que se lhe impóem.

\section{Palavras-chave}

Johann Baptist Metz, Teologia depois de Auschwitz, Memória, Cristologia, Mística.

¿Ha transformado la memoria de Auschwitz nuestro ser cristiano? ¿Somos, de hecho, una Iglesia "después de Auschwitz"? ¿O somos hoy, en cuanto cristianos, en cuanto Iglesia, igual que éramos ayer? En cuanto teólogos cristianos ¿seguimos hablando como hablábamos ayer, antes de Auschwitz?

(Johann Baptist Metz)

\section{INTRODUCCIÓN}

\subsection{La teología política en el contexto del Vaticano II}

El acontecimiento de Auschwitz y de la Shoá, del Holocausto judío, representa un punto crítico en la historia de la humanidad. La violencia del hombre sobre el hombre impactó en la reflexión humanista exigiéndole una palabra nueva sobre la defensa de la dignidad y de los derechos de toda persona humana. Una de esas reflexiones ha sido la teología católica, específicamente la del alemán Johann Baptist Metz (1928 - )³. Para Metz (2007) y para su biografía teológica, "Auschwitz señala un horror situado

3 Nació en Velluck, Alemania en 1928. Estudió en Bamberg e Innsbruck. Fue ordenado sacerdote en 1954. Desempeñó su labor docente en las Universidades de Munich y Münster. Discípulo de Karl Rahner. Su especialidad fue la Teología Fundamental. Se le conoce como el iniciador de la llamada Nueva teología política o Teología política crítica. Algunas de sus obras son "Teología del mundo", "La fe en la historia y la sociedad", "Más alla de la religión burguesa", "Memoria passionis" y "Dios y Tiempo". 
más allá de toda teología conocida, un horror que hace que todo discurso descontextualizado sobre Dios parezca vacío y ciego" (p.48). Desde este acontecimiento y como respuesta a la excesiva privatización en la que la teología cristiana se había visto envuelta como resultado de su repliegue en la época de la Ilustración, es que desarrolla el proyecto de la llamada "Teología Política crítica" o "Nueva teología política", la cual es entendida como un "correctivo crítico dentro de la teología actual” (Metz, 1968, p.384).

La teología política de Metz se sitúa dentro de la gran renovación teológica que sigue al Concilio Ecuménico Vaticano II (1962-1965). La década de los sesenta representa un periodo complejo pero también creativo tanto en la historia social y cultural como también en la historia de la Iglesia. Las intuiciones de Juan XXIII de aggiornar, de renovar la Iglesia, de abrir la ventana para que entre aire fresco, se manifestaron en una teología y en una praxis pastoral que se realizaría de cara al mundo, dialogando con la cultura y no condenando sus manifestaciones. Junto con ello, el reconocimiento de los aspectos positivos de la modernidad y la realización de un proceso de discernimiento de los signos de los tiempos de manera que se escuchara la voz y los silencios de Dios en la época presente. A juicio de J. Espeja (2000), dos teologías fueron significativas en la orientación del Vaticano II, a saber, la teología latinoamericana de la liberación y la teología política europea, las cuales están emparentadas tanto en su orientación social y política como también en la importancia de la praxis entendida como primer momento y la teología como momento segundo que busca comprender la acción concreta de los creyentes en el mundo.

La teología política buscó fundamentalmente dos cosas: en primer lugar, sugerir una nueva visión en la relación de la Iglesia con el mundo basada en una teología del mundo. A propósito de esto, Metz había afirmado que "todo concilio supone un nuevo punto de partida y le asigna a la teología nuevas tareas. Una de estas tareas es la de recrear la relación entre Iglesia y mundo. Como teólogo fundamental, Metz intenta exponer la fe en una forma que esté en consonancia con la actual situación histórica” (Ruz, 2010, p.70), en otras palabras, busca que su teología aparezca como significativa al momento de establecer puentes de diálogo con la cultura y la modernidad. El segundo elemento que busca la teología política, y que fundamenta nuestro artículo, es el que "ante los terribles genocidios como el que tuvo lugar a mediados del siglo XX en Alemania el interrogante parecía ineludible ¿̨tiene algo que 
decir aquí la fe cristiana? La respuesta es afirmativa, pero a condición de que los creyentes no guarden silencio, sino que renueven y desarrollen crítica y conscientemente la dimensión política de su fe" (Espeja, 2000, p.70).

\subsection{Las tareas de la Nueva teología olítica}

Metz propone su reflexión teológica como reacción particular a la crítica ilustrada nacida en Francia en la época moderna, en lo que se conoce como la "tarea negativa de la teología política". Ahora bien, es necesario reconocer que la crítica a la religión no es sólo patrimonio de la Ilustración, sino que ésta se expande en otras manifestaciones filosóficas, sociológicas o antropológicas, pero la mirada de Metz está puesta en la Ilustración. La crítica que la Ilustración realizó a la religión terminó relegando a la segunda al ámbito privado. H. Zirker (1985) sostiene que la crítica ilustrada logra que la Iglesia pierda aquellas competencias sociales que había venido desarrollando desde la edad media, en la cual Iglesia y Estado aparecían unidos, esto porque "todos los ámbitos de la vida tenían un carácter religioso tanto en su forma y expresión externa como en su contenido espiritual" (p.41). Con el paso a la época moderna acontece un cambio profundo, esto dominado por el giro hacia el hombre dejando de lado el dato de Dios como insignificante para la maduración racional del ilustrado, de aquél que puede pensar por sí mismo. La religión replegada hacia el ámbito privado y por tanto fundamentada en categorías ahistóricas y apolíticas, se caracteriza porque ya no forma parte integrante de la sociedad o como fundadora del sentido para el hombre.

La otra crítica que la religión sufre es la que proviene del marxismo, en donde "la religión es criticada como superestructura ideológica de una determinada praxis social y de determinadas relaciones de poder" (Gibellini, 1998, p.322). ¿Cuáles son los puntos centrales que Marx critica a la religión? En primer lugar, sostiene que la religión ya no expresa una conciencia comunitaria sino que es el medio de división, esto porque responde a intereses de ciertos grupos de poder. De esta noción aparece la conocida expresión de la religión como opio o adormecimiento del pueblo. La religión así queda relegada al espacio privado. Para Marx la religión rehúye de la conflictiva realidad histórica, con lo cual su propuesta ideológica es volver sobre la realidad concreta de tal manera que el hombre se haga cargo de su presente. 
Frente a este panorama de crítica ilustrada y marxista, ¿cuál fue la reacción de la teología? Sostiene Gibellini que "la teología reaccionó retirándose a la esfera de lo privado (...) privatizó este mensaje en su núcleo esencial y redujo la praxis de la fe a la decisión amundana del individuo (...) las categorías dominantes en esta teología para la explicación del mensaje son prevalentemente categorías de lo íntimo, de lo privado, de lo apolítico" (Gibellini, 1998, p.322), en definitiva, a vivir la fe como "una decisión de espaldas al mundo" (Metz, 1968, p.387). Frente a esta situación de la teología moderna, en la que ella ve al mundo como hostil y contrario al proyecto salvífico, Metz reacciona con la única teología que puede enfrentarse a esta privatización de la fe, a saber, la teología política crítica o nueva teología política, esto porque es la teología que "toma en serio la dimensión social y política de la existencia humana tal y como se comprende hoy día" (Geffré, 1969, p.356). El proyecto de Metz es lograr que la "Teología contribuya a que la palabra de la fe vuelva a ser una palabra no sólo privada, sino también socialmente eficaz" (Illanes y Saranyana, 1995, p.373).

Junto con la tarea de crítica a la excesiva y exagerada privatización de la fe producto de la crítica ilustrada y marxista en la que la teología se vio envuelta, encontramos la tarea positiva de la teología política. Esta tarea

consiste en desarrollar las implicaciones públicas y sociales del mensaje cristiano (...) se trata de responder críticamente a su desafío, asumiendo la tarea de desarrollar, también en teología, una nueva relación entre teoría y praxis. Y la teología puede hacerlo porque las promesas escatológicas de la tradición bíblica no son un horizonte vacío de espera religiosa, sino que tienen una dimensión pública que debe hacerse valer en su función crítica y liberadora en relación al proceso histórico social. (Gibellini, 1998, p.322)

Gracias a la explicitación de la tarea positiva de la teología política, o también llamada por Metz como "segunda reflexión" (Metz, 1968, p.387), comprendemos qué es lo que quiere decir Metz al hablar de politica. Lejos de significar una determinada opción partidista, expresa la profunda e insoslayable dimensión 'pública y social' del cristianismo, dimensiones que habían sido olvidadas a causa de las críticas modernas. Esta dimensión pública se divide a su vez en una vertiente crítica y liberadora en pos de un proceso histórico y social. Hay por tanto en la Nueva teología política una constante y necesaria referencia a la historia y a los procesos sociales en los cuales la fe se ubica como memoria, narración y solidaridad, conceptos 
fundamentales de la teología política. Esta función positiva de la teología política, en palabras de Metz, busca "determinar las relaciones existentes entre la religión y el cuerpo social, entre la Iglesia y la dimensión pública de la sociedad, entre la fe escatológica y la actividad social” (Metz, 1968, p.389).

\subsection{Plan de nuestro artículo}

Luego de esta breve introducción a la Nueva teología política de Johann Baptist Metz presentaremos algunas reflexiones que abordan la teología después de Auschwitz del teólogo alemán. En primer lugar, se evidencia cómo el acontecimiento de la Shoá impactó en la elaboración intelectual de Metz, especialmente en la utilización de categorías tales como cultura anamnética o la imposibilidad de una supuesta neutralidad cristiana post Auschwitz. En segundo lugar, abordar un tema específico de la teología de Metz, a saber, el pensar una cristología después de Auschwitz. Esta expresión hace alusión a la internalización por parte de la teología cristiana de que en Jesucristo acontece una identificación con el pueblo judío que padece la pasión y la muerte en los campos de concentración. Pensar el Misterio Pascual, esto es, la muerte y la resurrección de Jesucristo toma nuevos matices a la luz de la Shoá. Finalmente, se reflexiona en torno al desafío de pensar una mística política construida sobre la historia del sufrimiento. En Metz el tema de una mistica política, de una experiencia espiritual de ojos abiertos al sufrimiento y no de espiritualidades intimistas y apolíticas, representa un trabajo antropológico, social, educativo, religioso o cultural en el cual somos solidarios con los que sufrieron, con los que hoy sufren y con los que sufrirán. Esto finalmente constituye una experiencia auténticamente humana y compasiva.

\section{2. “SOY DE LA GENERACIÓN DE 'DESPUÉS DE AUSCHWITZ'": EL IMPACTO DE LA EXPERIENCIA DE LOS CAMPOS DE CONCENTRACIÓN EN METZ}

En repetidas ocasiones J. B. Metz ha sostenido que el acontecimiento del holocausto marcó profundamente su manera de hacer teología y de comprender qué lugar ocupa Dios en medio de la historia del sufrimiento humano. Metz comienza a utilizar la expresión de la teología o de la cristología 
"después de Auschwitz", la cual busca "sensibilizar al conjunto de la teología para las historias de sufrimiento, así como a enfocar con precisión la mirada de la teodicea del cristianismo a la situación de nuestro mundo" (Metz, 2007, p.46). ¿Cómo entiende Metz el acontecimiento de Auschwitz?, ¿por qué Metz emprende esta tarea de sensibilización?, ¿qué elementos propios del Cristianismo ha propiciado la llamada amnesia cultural que denuncia Metz?. Johann Baptist Metz entiende en primer lugar a Auschwitz como un "ultimátum" que le exige a la teología cristiana no permanecer impasible ante el dolor de las masas sufrientes. Nuestro autor sostiene que la teología que ha construido su reflexión de espaldas al Holocausto se fundamenta en una "llamativa apatía" (Metz, 2007, p.49) propia de su falta de sensibilidad a la teodicea, es decir, a la argumentación teológica que busca comprender cuál es el lugar de Dios en la historia del sufrimiento humano. Haciendo eco de su propuesta de la Nueva teología política que busca asumir lo político y lo social, la historia del hombre y las implicancias efectivas del mensaje cristiano, especialmente de la escatología o las promesas del Dios de Israel que es el Dios y Padre de Jesús, Metz sostiene que "es evidente que no existe ningún sentido de la historia que se pueda salvar de espaldas a Auschwitz, ninguna verdad de la historia que se pueda defender de espaldas a Auschwitz, ningún Dios al que se pueda adorar de espaldas a Auschwitz"4 (Metz, 2007, pp. 49-50). En este primer nivel se establece que la mística o el culto judío y cristiano que se celebra después del Holocausto no puede ser igual al que se venía realizando. Algo debe desencadenar en el creyente el "ultimátum" del dolor de los campos de concentración.

Si esto impacta en el creyente, el resultado es que en la teología cristiana vuelve a florecer una necesaria cultura anamnética, una cultura de la memoria. A juicio de Metz (2007), "para mantener Auschwitz, la Shoá, presente en la memoria como el desafío que en realidad representa, es preciso arraigar y apuntalar la conciencia teológica con ayuda de lo que yo llamo "cultura anamnética" (...) esta cultura anamnética es la dote del espíritu judío" (p.52). La memoria, concepto fundamental en la teología de Metz, y que pretende "lograr una comprensión dinámica, no estática, de la fe dogmática" (Metz, 1979, p.193), permite que el creyente pueda responsabilizarse de aquello que lo interpela hacia atrás, de lo que ha constituido su historia personal y social. Con esto, la Shoá vendrá a poner en tensión al sujeto con

4 Las cursivas son nuestras. 
la historia, de tal manera que ella sea percibida y aceptada "de manera tal que en ella no sólo se manifiesta lo alcanzado, sino también lo destruido, no sólo lo realizado, sino también lo perdido" (Metz, 2007, p.58). Con esto, Metz busca rescatar las voces judías silenciadas, las vencidas y sufrientes y desde ellas elaborar una teología que sea sensible al sufrimiento ajeno, de tal manera que sea consecuente con el mensaje de Jesús de Nazaret. Una de esas formas de pensamiento es la Cristología como veremos a continuación.

\section{PENSAR UNA CRISTOLOGÍA DESPUÉS DE AUSCHWITZ}

La teología de Metz se articula desde los "vencidos" y de su historia de sufrimiento. De ella se hace memoria passionis, memoria de la Pasión y de la Muerte, de la Cruz y de la muerte, pero también se realiza la memoria resurrectionis, el triunfo del Mesías Cristo y del juicio que se realiza sobre los vencidos, juicio que los constituye en vencedores en virtud del recuerdo que "trata de preservar la memoria peligrosa del Dios mesiánico, del Dios de la resurrección de los muertos y del juicio" (Metz, 1989, p.290). Esta memoria, que no es un mero entretenimiento, sino que es una categoría fundamentalmente política y teológica, le exige a la teología en general y a la cristología en particular abandonar una actitud de inocencia social y política. Los vencidos, los que sufrieron las consecuencias del dolor de los campos de concentración deben transformarse, a juicio de Metz, en "sujetos activos del lenguaje de la fe y de la teología, de un lenguaje en el cual la historia de la vida individual y la historia de la fe están juntamente entrelazadas" (Metz, 1989, p.290). ¿Qué significa que los vencidos son constituidos sujetos?, ¿por qué hablar de sujetos en la teología política, en la que quiere abandonar su inocencia social, en la que hace memoria de Auschwitz?

Para Metz, el sujeto "no es el individuo aislado" (Metz, 1979, p.77), sino que es quien está unido a los otros, sobre todo en "las experiencias de solidaridad y antagonismo, de liberación y angustia, compartidas con otros sujetos" (Metz, 1979, p.77). Aquí Metz utiliza la categoría de solidaridad universal o más específicamente el de solidaridad hacia atrás, para significar que el recuerdo de las víctimas de la historia del sufrimiento de la cual Auschwitz es paradigma debe interpelar la teología y exigirle una palabra a favor de los vencidos. Y del concepto de solidaridad bien sabe el mundo tanto de la 
Biblia Hebrea como del Nuevo Testamento cristiano. Solidaridad es Alianza, es pacto, éxodo, promesa de liberación y presencia de Dios en medio de su pueblo. Así sostiene nuestro autor que "las historias de fe del Antiguo y del Nuevo Testamento son historias de la dramática constitución de los hombres como sujetos, justamente mediante su relación con Dios. Los hombres son llamados a salir de las servidumbres y los miedos de las sociedades arcaicas; deben llegar a ser sujetos de una nueva historia" (Metz, 1979, p.77).

Ahora bien, para la teología cristiana Jesucristo constituye Aquél en quien reconocemos que la solidaridad se hace efectiva. Siguiendo la teología de San Pablo, quien nos dice que "por un hombre, Adán, entró el pecado al mundo, así por otro hombre, Jesús, entró la gracia sobreabundante" (Cf. Rm 5,12; 1 Cor 15,21). En Adán se logra la llamada solidaridad en el pecado y en Jesús de Nazaret, confesado como Verdadero Dios y Verdadero Hombre, mediador entre el Padre y los hombres (Cf. 1 Tim 2,5), se logra la solidaridad en la gracia y en la salvación. Jesucristo es pues el paradigma de este nuevo sujeto, del que es constituido en el sujeto por excelencia de la nueva historia, de la historia escatológica. Y esta esperanza es una de la que se hace memoria y narración, categorías políticas y centrales de la teología de Metz. Gracias a la memoria y especialmente a la narración, al arte de contar historias, se permite que se traigan al presente los sufrimientos de la Leindensgeschichte, la historia del sufrimiento, de manera de unir la praxis con la experiencia de los sujetos.

Ahora bien, ¿`cómo estos elementos antes mencionados y que son básicos en la doctrina cristológica se piensan "después de Auschwitz"?, ¿qué lugar ocupa Dios en la historia del sufrimiento? Para responder a estas preguntas, lo primero que Metz asume e invita a que el Cristianismo lo recuerde es que "Cristo no fue cristiano, sino judío" (Metz, 2001, p.113). Volver sobre los orígenes culturales, espirituales, sociales y políticos del judío Jesús implica asumir que el dolor del judaísmo ocasionado por el Holocausto es también el dolor del Cristianismo. Es más, y siguiendo la fórmula de Wiesel que trae Metz (2007) y que dice que "el cristianismo reflexivo sabe que en Auschwitz no murió el pueblo judío, sino el cristianismo" (p.47), confronta al creyente cristiano con el sufrimiento de su propio pueblo, con Aquél con el que Dios pactó primero la Alianza y que en él reconocemos una prefiguración de nuestra propia comunidad creyente. Así, "una cristología que se sienta vinculada a la historia de la fe de Israel y que, consciente de su negativa teológico-política anterior, pretende formularse prudentemente como 
"cristología después de Auschwitz" adquiere una luz nueva" (Metz, 2001, pp.113-114). Esta luz nueva es la que proporciona la memoria passionis y resurrecctionis del judío muerto y resucitado por Dios y que Metz articula en tres momentos.

En primer lugar, habla de una "cristología sensible a la cuestión de la teodicea” (Metz, 2001, p.114). En Auschwitz somos testigos del sufrimiento inmerecido, de la injusticia que la barbarie que el hombre realiza sobre el mismo hombre. Este sufrimiento, a juicio de Metz, fue abandonado por el cristianismo el cual centró su atención en el pecado, en la culpa. Con esto, "se entumecía la sensibilidad por el sufrimiento ajeno y oscurecía la visión bíblica de la justicia de Dios que, después de Jesús, había de valer para toda hambre y sed" (Metz, 2001, p.114). El desafío para la cristología y la teología después de Auschwitz es volver continuamente sobre la historia del sufrimiento y ver cuál es el lugar que Dios ocupa en ella, que en definitiva lejos de ser un rol de un ser violento es un Dios que salva especialmente al que sufre la injusticia.

En segundo lugar, Metz (2001) habla de una "cristología con conciencia apocalíptica" (p.114). La apocalíptica es un tema central tanto para el judaísmo como para el cristianismo. En la apocalíptica se hace memoria narrada del triunfo al final de los días de aquellos que han sufrido en la historia. No es una reflexión sobre los vencedores, sino que paradójicamente es sobre los vencidos. Para el cristianismo el núcleo de esta cristología con conciencia apocalíptica es la resurrección de Cristo la cual es paradigma de nuestra propia resurrección (Cf. 1 Cor 15). El Cristo que grita en la Cruz es el que es resucitado por Dios y hecho Señor de todo. El pueblo judío que clama al cielo en la Shoá es el que es reivindicado por Dios y del cual debe hacerse memoria subversiva, en el sentido de rescatar ese grito y asumir los desafíos que él nos impone.

El último elemento a considerar en la Cristología después de Auschwitz es la "cristología en el paradigma sinóptico" (Metz, 2001, p.114). Los evangelios sinópticos presentan una teología que acentúa el tema del seguimiento del discípulo, de la llamada de Jesús y de los milagros como signos de la presencia del Reino de Dios en la historia. Para Metz (2001), la historia sinóptica construida como seguimiento, permite la consecución de una liberación con conciencia de historia a la vez que permite "hacer accesibles los dogmas cristológicos como fórmulas de una memoria 
comprometida, arriesgada y liberadora de la Iglesia" (p.116). La cristología después de Auschwitz exige por tanto una mística del seguimiento del judío Jesús que retorne continuamente a la historia de los sufrimientos y que sea leída a la luz de los relatos de los evangelios sinópticos.

\section{EL DESAFÍO DE PENSAR UNA MÍSTICA POLÍTICA CONSTRUIDA SOBRE LA HISTORIA DEL SUFRIMIENTO}

Queremos finalizar nuestro artículo rescatando algunas reflexiones de J.B Metz sobre la necesidad de pensar y vivir una mística política que se construya sobre la historia del sufrimiento que, como vimos, posee a Auschwitz como paradigma.

El paso que Metz quiere dar es el de una mística del cristianismo marcada por la metafísica y lo trascendental a una que tenga conciencia de ser social y política. Una mística pensada en estos términos asume la historia del hombre, dramática y conflictiva, y puede responder mejor a los desafíos que la Modernidad le ha impuesto a la fe cristiana. Esta mística política nace cuando Metz (2002) recuerda que "ser cristiano significa ser cristiano mirando de cara a Auschwitz, mirando de frente al Holocausto; y de que para él hacer teología significa hacer teología con la vista puesta en Auschwitz, con la vista puesta en el Holocausto (...) porque el Holocausto no es sólo una catástrofe alemana sino una catástrofe cristiana” (p.110). ¿Cómo se vive una espiritualidad luego del genocidio nazi? ¿Cómo volver a orar luego de la sombra de muerte de los campos de concentración? La respuesta de Metz es por medio de una mística política que haga del creyente un sujeto políticamente sensible.

En la mística nos adentramos a la forma de relación con Dios por excelencia, la oración. ¿Se puede pues orar después de Auschwitz? Metz (2007) sostiene que sí, esto "porque también en Auschwitz se rezaba: en el canto, en el clamor de los prisioneros judíos" (p.48). Ahora bien, ¿qué características debe tener la oración realizada después de Auschwitz? Nuestro autor sostiene que "la oración fuerza al orante a seguir siendo sujeto y a no declinar su responsabilidad ante la propia culpa, le insta a hacerse sujeto frente a sus enemigos y en medio del miedo a perder su nombre y su cara, a 
perderse a sí mismo" (Metz, 1979, pp.77-78). La oración viene por tanto a constituir al creyente en un sujeto responsable de la historia que lo interpela desde atrás, de tal manera que proyecte una historia renovada hacia adelante. La relación con Dios, la oración, debe tornarse por ende social, es decir, debe implicar a los otros. No podemos vivir de una mística del intimismo ahistórico, sino que, exigidos por la muerte y el sufrimiento de los vencidos, volver a una mística política, a una fe que signifique "seguimiento del Jesús pobre, sufriente y obediente. Vivir en ese seguimiento significa tratar siempre con los hombres, actuar para ellos y con ellos de forma que en esta praxis se dé conjuntamente el reconocimiento de Dios" (Metz, 2002, p.112).

El ultimátum de Auschwitz se patentiza justamente en este desafío. No podemos ser cristianos como si Auschwitz o cualquier acontecimiento de dolor que afecte a nuestros pueblos latinoamericanos no involucre un despertar de sentimientos en nosotros. La mística política se sustenta en la cultura anamnética, en esa que evoca los recuerdos peligrosos del Dios bíblico que hace justicia a los vencidos. El dolor de las innumerables víctimas que elevan al cielo sus gritos debe volvernos solidarios "hacia atrás", con ellos y para que desde ellos podamos vivir la praxis política en favor de los sufrientes de hoy y de los que de seguro vendrán mañana. Por ello, la mística política es "una mística de resistencia frente a un mundo en el que los hombres son tratados y maltratados como si Dios no existiera" (Metz, 2002, p.112). Los creyentes, tanto judíos como cristianos, conscientes de nuestra tradición y de la memoria propia de nuestras respectivas culturas religiosas, debemos provocar justamente la defensa profética frente a aquellas situaciones que demandan un compromiso efectivo para con los vencidos, para con las víctimas de la historia del sufrimiento.

\section{CONCLUSIONES}

Finalmente, dos conclusiones. A nuestro entender, la teología política constituye un real aporte para pensar el acuciante sufrimiento de la historia del mundo, fundamentalmente por representar una toma de conciencia de la responsabilidad histórica de la Iglesia y de la sociedad respecto al porvenir del hombre y la transformación de la sociedad desde el rescate de la historia de los vencidos para que desde ella se asuma una nueva y decidida defensa de la dignidad de la persona humana. El sentido de la responsabilidad histórica 
no es menor, ya que coloca ante nosotros la exigencia de constituirnos comunidades creyentes y sociopolíticas compasivas, lo cual involucra un proceso de empoderamiento, de hacernos sujetos de nuestra propia historia, pero no sujetos aislados, sino preocupados los unos de los otros, especialmente de los que más sufren.

En segundo lugar, la relevancia teológica, eclesial y social de identificar aquellas situaciones de dolor y de atropello de los Derechos Humanos, que en otras palabras significa finalmente pasar de una vivencia intimista de la fe a una intelección y a un discurso teológico público y socialmente relevante. No podemos privatizar la historia del sufrimiento, no podemos desligarnos de toda la carga histórica que nos interrumpe y nos quiebra nuestros parámetros de supuesta seguridad. La necesidad de una ética del reconocimiento, de una cultura hermenéutica o interpretativa de los silencios forzados, de las voces calladas y los susurros tanto de Dios como de los demás seres humanos que nos hablan en la historia, debe lograr en nosotros una apertura y una vivencia de la alteridad especialmente con los sufrientes.

Frente a esto es que la teología política aparece como una instancia legítima y necesaria para poder proponer una nueva reforma eclesial en la que, desde nuestra identidad comunitaria, podamos reconocernos y reconocer a la sociedad política, religiosa y pluralista en la que nos encontramos. En definitiva, la teología política busca ser una teología del mundo, una reflexión creyente que haciéndose praxis mire la historia en la que vivimos, perciba y actúe en pos de los sufrimientos de la historia y que desde ella volver a anunciar la experiencia cristiana de Dios que quiere dialogar con la cultura de nuestro tiempo desde la mística política y la oración, desde el reconocimiento de la Shoá y de las situaciones actuales de injusticia y desde la conciliación de las miradas en pos de la liberación de las esclavitudes sociales, económicas, políticas, educativas o religiosas en la que permanecen muchos de nuestros contemporáneos.

\section{LISTA DE REFERENCIAS}

Espeja, J. (2000). Creer en este mundo. Madrid: Biblioteca de Autores Cristianos.

Geffré, C. (1969). Historia reciente de la teología fundamental. Intento de interpretación. Madrid: Concilium 46, 337-358. 
Johann Baptist Metz y la teología cristiana "después de Auschwitz"

Gibellini, R. (1998). La teología del siglo XX. Santander: Sal Terrae.

Illanes, J. Saranyana, J. (1995). Historia de la teología. Madrid: BAC.

Metz, J.B (1968). El problema de una teología política. Madrid: Concilium 36, 385-403.

Metz, J.B. (1979). La fe en la historia y la sociedad: Madrid: Cristiandad.

Metz, J.B. (1989). La teología en la lucha por la historia y la sociedad. En AA.VV. Teología y liberación, perspectivas y desafíos. Ensayos en torno a la obra de Gustavo Gutiérrez pp.285-296. Perú: Centro de Estudios Públicos.

Metz, J.B. (2002). Dios y tiempo. Nueva teología politica. Madrid: Trotta.

Metz, J.B. (2001). Hacia una cristología después de Auschwitz. Espańa: Selecciones de Teología 158, 111-116.

Metz. J.B. (2007). Memoria passionis. Una evocación provocadora en una sociedad pluralista. Santander: Sal Terrae.

Ruz, M. (2010). Nueva teología política. Desarrollo del pensamiento de Johann Baptist Metz. Córdoba: EDUCC.

Zirker, H. (1985). Critica a la religión. Madrid: Herder. 